\title{
A Retail Category Management Model Integrating Shelf Space and Inventory Levels
}

\author{
B. Ramaseshan ${ }^{a,}$, N. R. Achuthan ${ }^{\text {b }}$, R. Collinson ${ }^{b}$ \\ ${ }^{a}$ School of Marketing, Curtin University of Technology, Perth, Australia \\ ${ }^{\mathbf{b}}$ Department of Mathematics \& Statistics, Curtin University of Technology, Perth, Australia
}

*please send your comments to Ramaseshan B., Professor, School of Marketing, Curtin University of Technology, Perth , 6148, Western Australia. Phone: 61-8-9266 4674, Fax: 61-8-9266 3937, E-mail: ramaseshanb@cbs.curtin.edu.au

Achuthan, N.R., Department of Mathematics \& Statistics, Curtin University of Technology, Perth, 6148, Western Australia. Phone: 61-8-9266 7937, Fax: 61-8-9266 3197, E-mail: archi@ maths.curtin.edu.au

Collinson, R., Department of Mathematics \& Statistics, Curtin University of Technology, Perth, 6148, Western Australia. Phone: 61-8-9266 3209, Fax: 61-8-9266 3197, E-mail: $\underline{\text { R.Collinson@ curtin.edu.au }}$

\section{Acknowledgements}

The authors wish to thank Pierre Sequeira for providing store data so that the model could be tested in real-life conditions. The authors also wish to thank the Associate Editor and the anonymous referees for their valuable comments on the paper. 


\title{
A Retail Category Management Model Integrating Shelf Space and Inventory Levels
}

\begin{abstract}
A retail category management model that considers the interplay of optimal product assortment decisions, space allocation and inventory quantities is presented in this paper. Specifically, the proposed model maximizes the total net profit in terms of decision variables expressing product assortment, shelf space allocation and common review period. The model takes into consideration several constraints such as the available shelf space, backroom inventory space, retailer's financial resources, and estimates of rate of demand for products based on shelf space allocation and competing products. The review period can take any values greater than zero. Results of the proposed model were compared with the results of the current industry practice for randomly generated product assortments of size six, ten and fourteen. The model also outperformed the literature benchmark. The paper demonstrates that the optimal common review period is flexible enough to accommodate the administrative restrictions of delivery schedules for products, without significantly deviating from the optimal solution.
\end{abstract}

Key words: Category management, product assortments, optimal shelf space allocation. 


\section{A Retail Category Management Model Integrating Shelf Space and Inventory Levels}

\section{INTRODUCTION}

Many business organizations are forced to continually seek improvements in productivity due to the increasing costs in labor, space resources, volatile sales, and intense competition. Cachon (2001) emphasized the need for retailers to constantly strive for excellence in operations due to extremely narrow profit margins. The major contributing factors to retailers' costs are rental cost (Bultez and Naert 1988) and the opportunity cost of shelf space allocation to a product (Brown and Lee 1996). An efficient use of available shelf space and effective choice of product assortment would lead to increased retail productivity.

Recent developments in category management have focused on product categories rather than individual products/brands to investigate the performance of the retail industry. Campo and Gijsbrechts (2005) discuss the issues that interplay between retail assortment, shelf and inventory management and further emphasize the need to integrate these three decision areas of category management. The management of an independent franchise retailer requires recurring decisions including which products to stock (assortment decisions), how much shelf space to allocate for each product, the inventory order size of each product, and the frequency of assortment evaluation. The existing models in the literature do not address this important problem in an integrated manner from the perspective of an independent franchise retailer. The problems facing an independent retailer differ from those of other retailers, such as chain stores, in many ways. An independent retailer owns only one retail outlet, allowing him to make independent decisions and not tying up capital in other outlets. There is also the flexibility in choosing suppliers, retail formats and devising strategy. Customer segments can be selected instead of the mass market, so that product assortments, prices, and store hours are set consistent with the market. The main contributions of this paper are as follows: 
(i) The development of a non-linear mixed integer programming model that integrates product assortment, demand, shelf space, back room inventory space and inventory value restrictions in the context of independent franchise retailing.

(ii) The development of a heuristic method based on the Excel Solver add-in.

(iii) Illustration of the proposed methodology using examples with real life data drawn from an independent franchise retailer.

(iv) Comparison of the proposed method with the commonly used industry practice and also the simulated annealing method proposed by Borin et al. (1994).

The next section provides a brief background and review of the literature available in this area. This is followed by a presentation of the mathematical model for the category management problem introducing all the necessary notations and assumptions. In the next section, the methodology is illustrated through several examples generated from real life data arising from an independent franchise retailer. The conclusions are presented in the last section.

\section{BACKGROUND}

The existing category management models have evolved from the 1960's literature on the optimization of shelf space allocation (Brown and Tucker 1961; Lee 1961). Lee (1961) proposed a simple allocation model using shelf space elasticity as a demand effect. Curhan (1973) formalized the shelf space elasticity and provided a valuable synthesis of shelf space conceptual models and experiments exploring the relationship between the space allocated to a product and the unit sales of the product. A similar approach was adopted by Anderson and Amato (1974). Campo and Gijsbrechts (2005) provided a recent review of the literature in this area. Table 1 provides a brief outline of the subsequent literature in the area of shelf space allocation models and their main features. 
Table 1: List of some important contributions to shelf space allocation models

\begin{tabular}{|c|c|c|}
\hline Author(s) & The Model & Main features and method used \\
\hline $\begin{array}{l}\text { Hansen and } \\
\text { Heinsbroek } \\
\text { (1979) }\end{array}$ & $\begin{array}{l}\text { Shelf space allocation } \\
\text { model as a constrained } \\
\text { optimization problem. }\end{array}$ & $\begin{array}{l}\text { It is an extension of earlier models. Models the demand using the } \\
\text { shelf space elasticity, past sales and shelf space allocation. } \\
\text { Develops near optimal solution, using Lagrangian technique. }\end{array}$ \\
\hline $\begin{array}{l}\text { Corstjens } \\
\text { and Doyle } \\
\text { (1981) }\end{array}$ & $\begin{array}{l}\text { Shelf space allocation } \\
\text { model. }\end{array}$ & $\begin{array}{l}\text { Extends Hansen and Heinsbroek (1979) model by incorporating } \\
\text { cross elasticities within the demand formulation. Develops } \\
\text { branch and bound method. }\end{array}$ \\
\hline $\begin{array}{l}\text { Corstjens } \\
\text { and Doyle } \\
\text { (1983) }\end{array}$ & $\begin{array}{l}\text { Dynamic shelf space } \\
\text { allocation model. }\end{array}$ & $\begin{array}{l}\text { Extends their previous model to a dynamic model incorporating } \\
\text { product life cycle and consumer preference. Develops near } \\
\text { optimal solution. }\end{array}$ \\
\hline $\begin{array}{l}\text { Zufryden } \\
(1986)\end{array}$ & $\begin{array}{l}\text { Dynamic programming } \\
\text { formulation of shelf } \\
\text { space allocation model. }\end{array}$ & $\begin{array}{l}\text { Extends the model by Corstjens and Doyle (1981) incorporating } \\
\text { space elasticity and non-space factors such as price, advertising, } \\
\text { and promotion. }\end{array}$ \\
\hline $\begin{array}{l}\text { Bultez and } \\
\text { Naert } \\
\text { (1988) }\end{array}$ & $\begin{array}{l}\text { SH.A.R.P. } \quad \text { Shelf } \\
\text { Allocation for } \\
\text { Retailers Profit) model. }\end{array}$ & $\begin{array}{l}\text { Extended the work of Corstjens and Doyle }(1981,1983) \text { and its } \\
\text { application. They estimated space elasticities using a symmetric } \\
\text { attraction model. }\end{array}$ \\
\hline $\begin{array}{l}\text { Bultez et } \\
\text { al. (1989) }\end{array}$ & SH.A.R.P. II model. & $\begin{array}{l}\text { This is an extension of SH.A.R.P. model integrating it with an } \\
\text { asymmetric variant attraction model for the cross elasticities. }\end{array}$ \\
\hline $\begin{array}{l}\text { Bookbinder } \\
\text { and Zarour } \\
\text { (2001) }\end{array}$ & $\begin{array}{l}\text { Shelf space allocation } \\
\text { model. }\end{array}$ & $\begin{array}{l}\text { This model incorporates Direct Product Profitability (DPP) } \\
\text { considerations within the model by Corstjens and Doyle (1981). }\end{array}$ \\
\hline
\end{tabular}


Yang (2001) considered a simple shelf space allocation model to maximize the store profit constrained only by the length of the shelf, the length of the product, the product profit per facing and bounds on number of facings. The author proposed a heuristic algorithm to solve this as a multi constrained knapsack problem, but optimal solutions were only found to simplified versions of the original model. Lim, Rodrigues, and Zhang (2004) developed metaheuristic methods such as Tabu search and a Squeaky Wheel Optimization to solve the simplistic model proposed by Yang (2001), as well as a simplified version of the Corstjens and Doyle (1981) model. Recently, Chen and Lin (2007) explored the data mining approach to product assortment and shelf space allocation. The first category management model that integrates the shelf space allocation and the inventory decisions was developed by Borin, Farris, and Freeland (1994). Table 2 provides a brief account of the category management models available in the literature.

Table 2: Integrated category management models

\begin{tabular}{|c|c|c|}
\hline Author(s) & The Model & Main features and method used \\
\hline $\begin{array}{l}\text { Borin et al. } \\
\text { (1994). }\end{array}$ & $\begin{array}{l}\text { Category } \\
\text { management. }\end{array}$ & $\begin{array}{l}\text { This constrained optimization model integrates shelf space allocation } \\
\text { and its influence on demand. They developed a heuristic method based } \\
\text { on simulated annealing to maximize the category return on inventory. }\end{array}$ \\
\hline $\begin{array}{l}\text { Urban } \\
\text { (1998) }\end{array}$ & $\begin{array}{l}\text { Integrated } \\
\text { category } \\
\text { management. }\end{array}$ & $\begin{array}{l}\text { This model improves the model of Borin et al. (1994) by separating the } \\
\text { consequences of backroom and displayed inventories and by keeping } \\
\text { track of the competitive and complementary product considerations. } \\
\text { They provided a gradient reduction algorithm and a genetic algorithm to } \\
\text { find near optimal solutions while maximizing the average net profit. }\end{array}$ \\
\hline $\begin{array}{l}\text { Hwang et al. } \\
(2005)\end{array}$ & $\begin{array}{l}\text { Integrated } \\
\text { category } \\
\text { management. }\end{array}$ & $\begin{array}{l}\text { The model distinguishes the product display levels in the shelf. A } \\
\text { gradient search heuristic and a genetic algorithm were proposed to solve } \\
\text { the model while maximizing the average net profit. }\end{array}$ \\
\hline
\end{tabular}


Apart from the academic literature, commercial software programs such as Apollo (Information Resources) and Spaceman (ACNielsen) have contributed to the area of allocation of shelf space through non optimal methods. The types of factors relevant to allocation of space considered by these programs are turnover, gross profit margins and constraints such as inventory costs. Although such programs assist in investigating alternate shelf space allocations through simulation (Dreze et al. 1994), these software packages can not be considered as optimization tools (Desmet and Renaudin 1998).

Over the years the emphasis of shelf space and product assortment models research has shifted towards an integrated category management optimization model. Retail managers are required to make a number of vital decisions that include what products to stock on the shelf (assortment decisions), the number of facings to allocate to each product (shelf space allocation decisions), the ordering levels, and the frequency of category assortment evaluation or review. Such decisions are all dependent upon the accurate estimation of demand and available inventory space.

In order to understand the current industry practice and the usage of the existing models, detailed interviews were conducted with small and medium size independent franchise retailers. It was noted that the current decision processes (regarding product assortment and space allocations) used by retailers are ad hoc. In fact, the retailers lack an understanding of the alternative decision strategies that could improve their profit. Further, it was found that the space decisions were made through either a share-of-salesequals-share-of-space rule, or planograms designed by high market share manufacturers such as Kellogs and Coca-Cola, or those designed by the franchiser. In general, these planograms do not take note of the individual independent franchisee's interests such as demand or contribution to net profit that is relevant to the specific geographic location of the retailer. Some of the retailers expressed a keen interest in exploring alternative methods of determining optimal review periods. 
The model presented in this paper specifically addresses the issue of product assortment, shelf space allocation, back room inventory, monetary restriction on inventory and the optimal period of review (evaluation) by considering demand as a function of allocated shelf space and the cross-elasticities of competing products.

At first glance the proposed model may be viewed as an extension of one of the models proposed by Borin et al. (1994), Urban (1998), or Hwang et al. (2005). The following observations reiterate the benefits of our proposed model and the suggested methodology:

(i) The category management model proposed by Borin et al. (1994) maximizes the category return on inventory. The integrated category management models of Urban (1998) and Hwang et al. (2005) maximize the average net profit per unit time. But the independent franchise retailer would rather maximize the expected total net profit accumulated for a group of competing products of a category during a common review period for them. The proposed model uses this objective function which is relevant to the independent franchise retailer.

(ii) The model proposed by Borin et al. (1994) is not explicit in its formulation and hence its applicability may not be satisfactorily validated. In fact their formulation does not include restrictions on back room inventory and monetary levels. The integrated category management models of Urban (1998) and Hwang et al. (2005) also exclude monetary restrictions that are vital to the independent franchise retailer. The model proposed by Hwang et al. (2005) does not include product assortment. The model proposed in this paper is in an explicit form and direcly addresses the needs of independent franchise retailers.

(iii) The proposed simulated annealing heuristic of Borin et al. (1994) does not use any of the constraints of their model in an explicit form. The gradient search heuristics proposed by Urban (1998) and Hwang et al. (2005) are partially based on their models, but not implemented in the commonly available Excel environment. Our proposed methodology is 
explicit and permits modeling of many of the commonly occurring constraints in the Excel environment.

\section{PROPOSED INTEGRATED CATEGORY MANAGEMENT MODEL}

In this section we present a category management model that maximizes the expected total net profit accumulated during a common review period for an independent franchise retailer. Our model differs from previous approaches on two levels. First, the model incorporates the considerations of space allocation, product assortment determination, inventory quantities, retailer's financial resources, demand and the determination of the common review period. Second, the planning horizon for the model is flexible, depending on the needs of the retailer.

The assumptions and notations required for the proposed model are:

1. Let $N=\{1 \ldots n\}$ denote the set of products that are included in the model from a specified category (for example, say from 'Hot Beverages or Soft Drinks') such that they are competing with each other for the limited shelf space and backroom inventory space.

2. The time period between two consecutive reviews of stocks (for ordering and replenishing the backroom inventory of all the products in the category) is called the review period. The proposed model assumes a common review period for all the products of the category. Furthermore, this review period is a decision variable of the model and is denoted by $t$.

3. The objective is to maximize the expected total net profit during the review period of length $t$, considering that all the related monitory transactions are often carried out exactly once in every review period.

4. The decision variable $s_{j}$ denotes the number of shelf facings allocated to product $j$, for $j$ in $N$. Let $\ell_{j}(\geq 0)$ and $u_{j}$ respectively denote the lower and upper bounds on $s_{j}$. The variable $z_{j}$ is defined through a constraint $s_{j}\left(1-z_{j}\right)=0$ so that a positive allocation of shelf space for product 
$j$ forces $z_{j}$ to be 1 . Furthermore, for an optimal solution, the maximizing objective function forces the model to choose $z_{j}$ at zero level when $s_{j}=0$. Next, the variable $r_{j}$ (used in modeling the demand) is defined using the constraint $r_{j}=\left(1-z_{j}\right)+s_{j} z_{j}$ such that $r_{j}=s_{j}$ or 1 according to whether $s_{j}$ is positive or zero respectively. Let $C_{s, j}$ denote the fixed shelf space cost per facing for product $j$.

5. The average (expected) demand rate (that is demand per unit time) of product $j$ is denoted by $d_{j}$. The expected demand $d_{j}$ per unit time is modeled in the typical polynomial form as a function of $\alpha_{j}$, the potential expected sales; $s_{j}$, the number of shelf facings allocated to product $j ; \beta_{j}$, the space elasticity for product $j$ corresponding to one shelf facing; $\delta_{j k}$, the cross elasticity between product $j$ and product $k$ which can be either negative (substitutable competitive relationship) or positive (complementary relationship); and $\lambda_{i}$, the resistance of a customer to compromise in the situation where the desired product $i$ is not included within the assortment.

More precisely, the expected demand rate $d_{j}$ is modeled (Borin et al. 1994) as follows: Let $N^{+}=$ $\left\{j: j\right.$ is in $N$ and $\left.s_{j}>0\right\}$, that is the set of products included in the product assortment. Let $N^{-}=$ $N-N^{+}$, that is the set of products excluded from the product assortment. Further, in the following model for the expected demand $d_{j}$ we take $s_{j}=1$ whenever $j$ is an element of $N^{-}$.

$$
d_{j}=\alpha_{j} s_{j}^{\beta_{j}}\left[\prod_{k \in N^{+}} s_{k}^{\delta_{j k}}\right]\left[1+\sum_{i \in N^{-}}\left(-\lambda_{i}\left(\frac{\delta_{i j} \alpha_{j} s_{j}^{\beta_{j}}\left[\prod_{k \in N^{+}} s_{k}^{\delta_{j k}}\right]}{\sum_{m \in N^{+}} \delta_{i m} \alpha_{m} s_{m}^{\beta_{m}}\left[\prod_{k \in N^{+}} s_{k}^{\delta_{m k}}\right]}\right]\right)\right]
$$

The term $\alpha_{j} s_{j}^{\beta_{j}}\left[\prod_{k \in N^{+}} s_{k}^{\delta_{j k}}\right]$ represents the modified demand for a product $j$ and incorporates the effect of shelf space elasticities and cross elasticities given a product assortment set $N^{+}$. The 


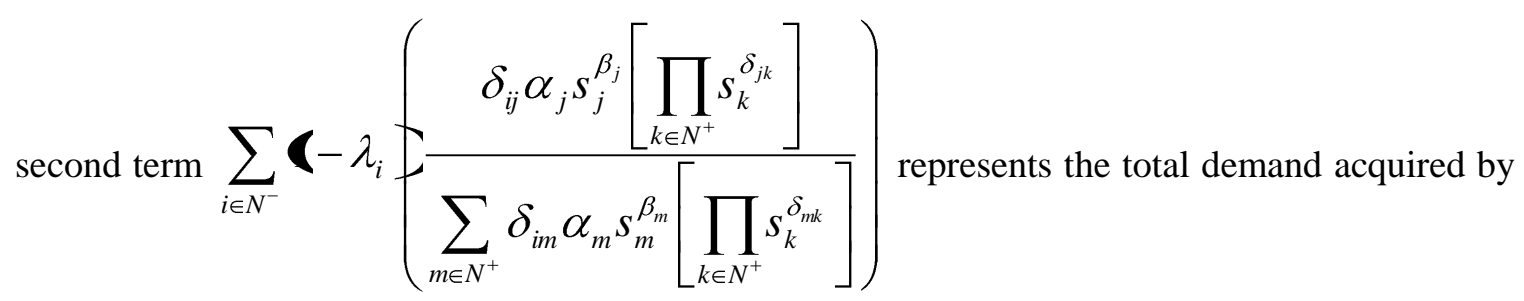

a product $j$ from the set of products excluded from the product assortment, that is in $N^{-}$. The acquired demand is dependent upon the resistance of consumers of product $i$ to compromise purchase intention and switch to product $j$, and is measured by $\lambda_{i}$. The volume of acquired demand is also moderated by the relative share of shelf space of product $j$ to the total space allocated to the set of products $N^{+}$included in the assortment. Using the variables $z_{j}$ and $r_{j}$ one can remodel the expected demand rate in terms of $s_{j}, r_{j}, z_{j}$ and $N$ as follows: $d_{j}=\alpha_{j} s_{j}^{\beta_{j}}\left[\prod_{k \in N} r_{k}^{\delta_{j k}}\right]\left[1+\sum_{i \in N}\left(-\lambda_{i}\left(1-z_{i}\right)\left(\frac{\delta_{i j} \alpha_{j} r_{j}^{\beta_{j}}\left[\prod_{k \in N} r_{k}^{\delta_{j k}}\right]}{\sum_{m \in N} \delta_{i m} \alpha_{m} s_{m}^{\beta_{m}}\left[\prod_{k \in N} r_{k}^{\delta_{m k}}\right]}\right]\right]\right.$.

Note that in this modeling of $d_{j}$ whenever allocated shelf space $s_{j}$ is zero, the model forces $d_{j}$ to be zero, though the basic expected sales $\alpha_{j}$ is positive.

6. The parameters used in the modeling of $d_{j}$ are estimated either from the past data or from specially conducted experiments.

7. Note that the per unit time potential sales is a random variable and its mean is estimated as the potential expected sales $\alpha_{j}$ from the past sales data for product $j$.

8. Note that the model uses the proportionality assumption and thus the order quantity for the review period of length $t$ is equal to the expected potential demand during the review period and that is equal to $t d_{j}$ for product $j$. The managers would prefer to set the order quantity for the review period of length $t$ as $t d_{j}+S S_{j}$ where $S S_{j}$ is the safety stock determined on the basis of the stochastic behavior of the potential demand, the cost of idle inventory, and the cost and risk of out 
of stock situation for product $j$. The present model assumes that $S S_{j}$ is zero. Let $Q_{j}^{\min }$ and $Q_{j}^{\max }$ respectively denote the lower and upper bounds on the number of units ordered of product $j$.

9. The shelf space is continuously replenished from the backroom inventory.

10. Let $p_{j}$ and $c_{j}$ denote respectively the retail price and the purchasing cost of one unit of the product $j$. Let $C_{o, j}$ denote the fixed procurement (ordering and receiving) cost of product $j$ for every delivery. Note that $C_{o, j}$ does not depend on the delivered quantity. Let $C_{h, j}$ denote the fixed backroom storage cost per unit of product $j$ irrespective of the duration of storage.

11. Since the model uses a short time planning horizon, it is reasonable to assume that all the cost parameters are constant and do not change with time during the planning horizon. Furthermore, the model can be resolved with appropriate changes to the cost parameters while planning a sales promotion with the supplier for some of the products.

12. Let $B_{S L}, B_{S W}$ and $B_{S H}$ respectively denote the length, depth and height of the available shelf space. The volume of the available shelf space is equal to $B_{s}=\left(B_{S L}\right)\left(B_{S W}\right)\left(B_{S H}\right)$.

13. Let $b_{s \ell j}, b_{s w j}$ and $b_{s h j}$ denote respectively the length, depth and height of one unit of product $j$. The volume of one unit of product $j$ is $b_{j}=\left(b_{s \ell j}\right)\left(b_{s w j}\right)\left(b_{s h j}\right)$. Note that the product $j$ can be displayed in the shelf with either depth facing or length facing and it is given by $F_{j}=\left\{\begin{array}{l}\mathrm{W}-\text { if depth facing required. } \\ \mathrm{L}-\text { if length facing required. }\end{array}\right.$. Furthermore, for some products its height $b_{s h j}$ compared to shelf's height $B_{S H}$ permits vertical stacking. The stack-ability of product j is given by $S P_{j}$ which assumes value 1 or 0 according as the product $j$ is stackable or not.

14. Let $k_{j}$ denote the maximum number of items of product $j$ that can be stored on the shelf given an allocation of one facing, and the facing requirement $F_{j}$ of product $j$. 
Note that, $k_{j}= \begin{cases}\left.\left\lfloor\frac{B_{S H}}{b_{s h j}}\right\rfloor \frac{B_{S W}}{b_{s \ell j}}\right\rfloor, \text { if } F_{j}=W, & \text { or }\left\{\begin{array}{l}\left\lfloor\frac{B_{S W}}{b_{s \ell j}}\right\rfloor, \text { if } F_{j}=W, \\ \left.\left\lfloor\frac{B_{S H}}{b_{s h j}}\right\rfloor \frac{B_{S W}}{b_{s w j}}\right\rfloor, \text { if } F_{j}=L,\end{array} \quad \text { according to }\right.\end{cases}$ whether $S P_{j}$ is equal to 1 or 0 respectively. Thus if product $j$ is allocated $s_{j}$ shelf facings then the number of items of product $j$ that will be accommodated on the shelf is $s_{j} k_{j}$.

15. Let $B_{b}$ denote the volume of available backroom inventory space. Similarly let $M_{I}$ denote the upper bound on the maximum money value of the idle capital in the form of the total inventory on hand at any point of time.

16. It is also assumed that no stock is currently on hand by the retailer which can be used to cater for expected sales.

\section{Mathematical formulation}

$\operatorname{Maximize} \prod_{n}=\sum_{j \in N} \boldsymbol{Q}_{j}-c_{j} \grave{t g} d_{j}-C_{o, j} z_{j}-C_{s, j} s_{j}-d_{j}-s_{j} k_{j} \grave{C}_{h, j}$

subject to

$$
\begin{aligned}
& \sum_{\substack{F_{j}=W \\
j \in N}} b_{s w j} s_{j}+\sum_{\substack{F_{j}=L \\
j \in N}} b_{s \ell j} s_{j} \leq B_{S L}, \\
& \sum_{j \in N} b_{j} s_{j} k_{j} \leq B_{s}, \\
& \sum_{j \in N} b_{j}\left(t d_{j}-s_{j} k_{j}\right) \leq B_{b}, \\
& \sum_{j \in N} c_{j}\left(t d_{j}\right) \leq M_{I}, \\
& t d_{j} \leq Q_{j}^{\max }, \quad j \in N, \\
& t d_{j} \geq Q_{j}^{\min } z_{j}, \quad j \in N,
\end{aligned}
$$




$$
\begin{aligned}
& s_{j} k_{j} \leq t d_{j}, \quad j \in N, \\
& \ell_{j} \leq s_{j} \leq u_{j}, \quad j \in N, \\
& s_{j}\left(1-z_{j}\right)=0, \quad j \in N, \\
& r_{j}=\left(1-z_{j}\right)+s_{j} z_{j}, \quad j \in N, \\
& d_{j}=\alpha_{j} s_{j}^{\beta_{j}}\left[\prod_{k \in N} r_{k}^{\delta_{j k}}\right]\left[1+\sum_{i \in N}\left(-\lambda_{i}\left(1-z_{i}\right)\left(\frac{\delta_{i j} \alpha_{j} r_{j}^{\beta_{j}}\left[\prod_{k \in N} r_{k}^{\delta_{j k}}\right]}{\sum_{m \in N} \delta_{i m} \alpha_{m} s_{m}^{\beta_{m}}\left[\prod_{k \in N} r_{k}^{\delta_{m k}}\right]}\right]\right), j \in N,\right.
\end{aligned}
$$

(Note that the expected demand $d_{j}$ is modeled as detailed in Assumption 5.)

$$
z_{j} \geq 0 ; z_{\mathrm{j}} \leq 1 ; \quad z_{j} \leq s_{j} ; s_{j} \text { integer } j \in N
$$

The objective function (1) maximizes the expected net profit accumulated during the review period and it is equal to the gross revenue subtracted by procurement costs, shelf space costs and backroom inventory costs. Note that the contributions to the objective function by a product $j$ in $N$ during a review period of duration $t$ are (i) the gross revenue: $\left(p_{j}-c_{j}\right) t d_{j}$; (ii) the procurement cost: $-C_{o, j} z_{j}$; (iii) the shelf space cost: $-C_{s, j} s_{j}$; and, (iv) the backroom inventory cost: $-C_{h, j}\left(t d_{j}-s_{j} k_{j}\right)$.

Constraint (2) restricts the sum of the allocated linear metric space of the shelf allocation to be less than or equal to the available shelf space length, $B_{S L}$ with the given values of $F_{j}$. Constraint (3) ensures that the total volume of products allocated to the shelf space is less than or equal to the available shelf space volume $B_{s}$. Next, constraint (4) restricts the total volume of the backroom inventory space of the products in the assortment to be less than or equal to the total volume of the backroom inventory space, $B_{b}$. Similarly, the constraint (5) assures that the total idle money locked up in inventory (both backroom and shelf) will not exceed $M_{I}$ at any point of time. 
In order to satisfy the expected sales during period $t$ we take the order quantity as $t d{ }_{j}$ given that the rate of demand is $d_{j}$. Constraints (6) and (7) place an upper $\left(Q_{j}^{\max }\right)$ and lower $\left(Q_{j}^{\min }\right)$ order limit on the quantity ordered for each product $j$. These upper and lower limits permit the retailer to strategically model situations that arise due to demand during product life cycle or unexpected events or constraints imposed by supplier (Corstjens and Doyle 1983). Constraint (8) states that the quantity ordered must be greater than the number of units required to be stored on the shelf given the allocation of $s_{j}$ facings.

The constraint (9) places lower and upper limits on the number of facings $\left(s_{j}\right)$ to be allocated to a product $j$. Often such constraints arise from administrative convenience, contractual obligations between supplier and retailer.

A product is excluded from the category assortment if it is not allocated a shelf facing. The constraints (10) and (11) define respectively the variables $z_{j}$ and $r_{j}$. The next constraint (12) recollects the modeling of the expected demand $d_{j}$. Finally, the constraint (13) ensures that $z_{j}$ is non-negative and at most equal to $s_{j}$. Note that in our model the product assortment is decided through the shelf space allocation $s_{j}$ by virtue of selecting $s_{j}$ to be zero. On the other hand Urban (1998) considered them as distinct problems.

\section{PRACTICAL EVALUATION OF THE PROPOSED MODEL}

From the interviews conducted with independent franchise retailers, it was found that the current practice is to allocate shelf space for a product approximately equal to its market share. This is the most commonly used allocation method by practitioners (Borin and Farris 1995). The aim of this section is to carry out extensive comparisons of our model with the current practice. 
A number of studies (Sandgren (1981), Haggag (1981), Kao (1988) on a variety of problems, including applications in optimizing the inventory and shelf space allocation model (Urban, 1998; Kar et al., 2001), have been undertaken showing that the GRG is a robust and reliable approach to solving nonlinear programming problems. Colville (1968) conducted a comprehensive comparison of fifteen codes from industrial firms and universities and Generalized Reduced Gradient (GRG) was ranked the best method among them. In particular, the method was found to be consistent in programs used to solve real-life industrial problems.

We note that neither GRG nor any other nonlinear optimization package can guarantee finding the global optimum in cases where there are distinct local optima. The only exception is if the problem is convex, in which case any local optimum is also global. The proposed search method overcomes some of these drawbacks by generating several initial solutions that are used as input for the GRG method to develop a set of local optimum solutions. Furthermore, the search method uses a rounding heuristic to search around the generated local optimum solutions for the feasible solutions of our model. In the process the method generates a number of feasible solutions and selects the best in terms of the objective function value.

Ramaseshan, Achuthan and Collinson (2008) developed a Category Management Decision Support Tool $(C M D S T)$ in the environment of Microsoft Excel using its spreadsheet capabilities, Visual Basic for Applications and an add-in facility called Solver (Frontline Systems). This was done keeping in view the inexpensive and easy accessibility of Microsoft Excel software to independent retailers. The CMDST has user driven menus to enter input data and choose optimizing criteria. The CMDST is a search method developed for the underlying model with a user specified limit on the number of iterations. It uses the following call routines: Init_Solution, Random_Init_Solution, Solver and Round. At each iteration $i$, the best solution $S_{i}^{*}$, from a set of feasible solutions is compared with the best known solution $S_{\text {best }}$ and updated if necessary. 
The pseudo code of CMDST is shown in Figure 1.

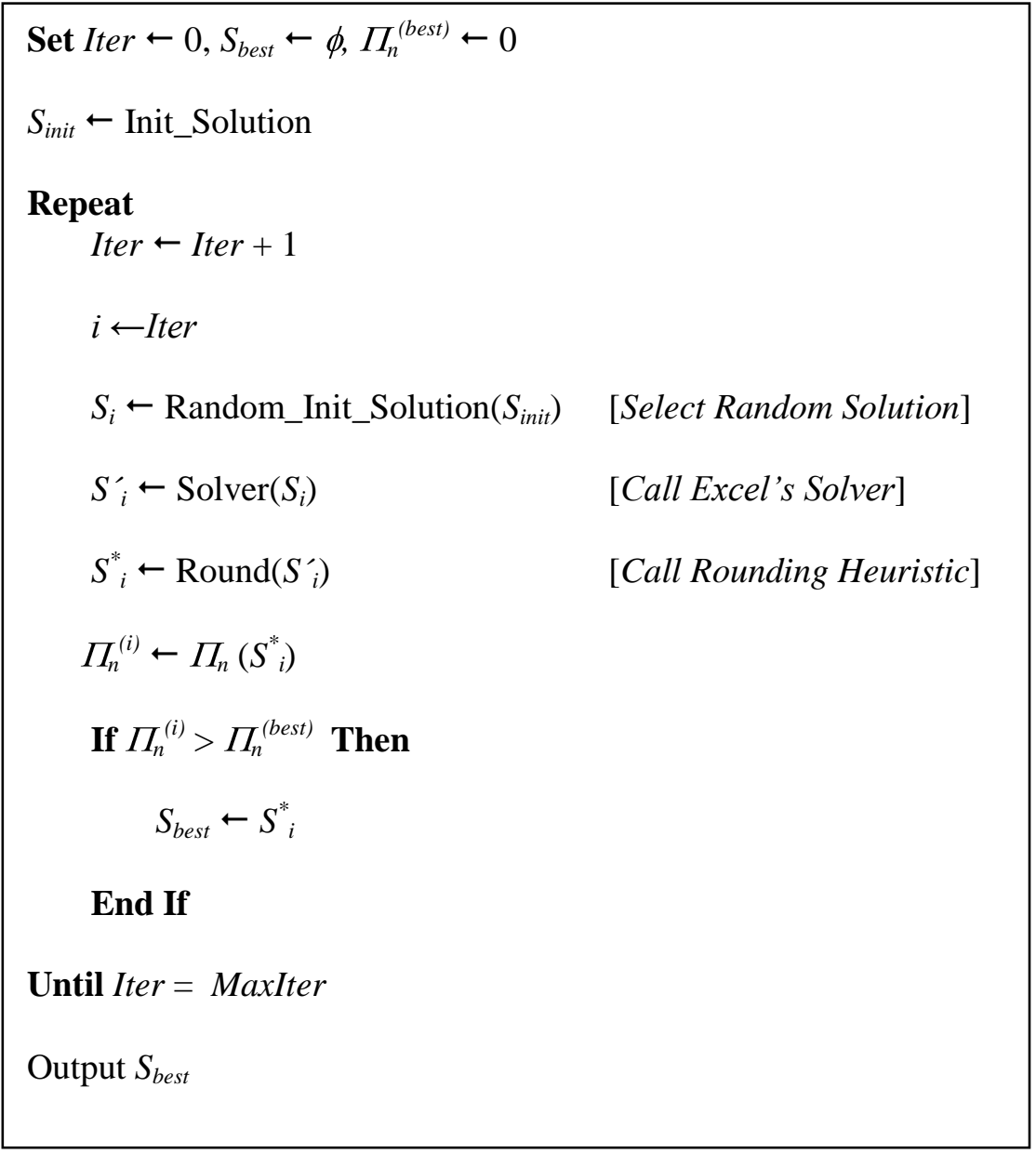

Figure 1. Pseudo Code of the proposed Search Method.

In the following we briefly outline the important features of the call routines used in our search method.

\section{Init_Solution :}

1. Fix the variable $d_{j}=\alpha_{j}$, the estimated average per unit time demand of the product $j$ and consider the reduced problem (1) - (9) and (13). 
2. Solve the reduced relaxed problem (1)- (9) and (13) relaxing the integer restrictions on $s_{j}$ and $z_{j}$. Note that this relaxed problem is a Linear Programming Problem and can be solved by the Solver. Let the solution obtained by the Solver be denoted by $S_{i n i t}=\left(t, s_{j}, z_{j}, d_{j}\right)$. Note that if $S_{\text {init }}=\left(t, s_{j}\right.$, $z_{j}, d_{j}$ ) satisfies (10) to (12) then it is a feasible solution to the relaxed problem (1) to (13), relaxing the integer restrictions.

3. When $S_{\text {init }}=\left(t, s_{j}, z_{j}, d_{j}\right)$ does not satisfy $(10)-(12)$ we perform the following steps:

(a) If $s_{j} \leq 0.1$ and $s_{j}\left(1-z_{j}\right)>0$ then fix $s_{j}=0$ and $d_{j}=0$.

(b) If $s_{j} \geq 0.9$ and $s_{j}\left(1-z_{j}\right)>0$, then fix $z_{j}=1$.

(c) If $0.1<s_{j}<0.9, s_{j}\left(1-z_{j}\right)>0$ and $\left(1-z_{j}\right) \leq 0.1$, then fix $z_{j}=1$.

(d) Revise the non zero $d_{j}$ by the constraint (12) using $r_{k}=\max \left\{1-z_{k}, s_{k}\right\}$.

(e) Consider the reduced problem (1) - (9) and (13) eliminating the variables

that are fixed by steps (a) to (c).

4. Repeat steps (2) and (3) until $S_{\text {init }}=\left(t, s_{j}, z_{j}, d_{j}\right)$ satisfies (2) - (13), relaxing the integer restrictions.

\section{Random_Init_Solution $\left(S_{\text {init }}\right)$ :}

1. Using the initial solution $S_{\text {init }}=\left(t, s_{j}, z_{j}, d_{j}\right)$, determine for each product $j$, the integer interval $I_{j}=$ $\left[0, \mid s_{j} \quad\right]$. Select a random integer $k$ between $\left\lfloor\frac{n}{4}\right\rfloor$ and $\left\lfloor\frac{n}{2}\right\rfloor$. The choice of this interval was 
made after investigating several alternatives. Then choose $k$ products at random from the set of $n$ products.

2. Define a new reduced problem on $(n-k)$ products by fixing the levels of the $k$ chosen products in the formulation (1) to (13). If a product $j$ is one among the $k$ chosen products, then fix the variable $s_{j}$ as a random integer from the Interval $I_{j}$. If $s_{j}$ is fixed as zero, then revise the variables $z_{j}$ and $d_{j}$ also as zero. If $s_{j}$ is fixed as a non zero value, then fix $z_{j}$ as 1 and $d_{j}$ by (12). Next, construct the new reduced problem with $(n-k)$ products eliminating the $k$ products from the model (1) to (13).

3. Apply the procedure Init_Solution to the reduced problem on $(n-k)$ products. Let $S_{i}$ denote the solution obtained by the application of Init_solution to the reduced problem. For notational convenience, the solution $S_{i}$ will include the details for all the $n$ products of the original problem.

\section{Solver $\left(S_{i}\right)$ :}

The Solver add-in program consists of two computer programs. The first is an Excel Visual Basic program used to convert the spreadsheet model to an internal representation used by the second program. While the second program, an independent software module, optimizes the model using a variant of the Generalized Reduced Gradient (GRG) method, GRG2, and returns the solution to the first. GRG is a generalization of the reduced gradient method by allowing nonlinear constraints and arbitrary bounds on the variables. If the model and constraints are linear this procedure reduces to the Simplex Method, and if no constraints are present it is a gradient search. In the $i^{\text {th }}$ iteration of our method the solution $S_{i}$ (generated by Random_Init_Solution) is used as an initial solution to the Solver. The output of Solver is dented by $S_{i}^{\prime}$.

\section{$\operatorname{Round}\left(S_{i}{ }^{\prime}\right)$ :}

The output $S_{i}^{\prime}$ of Solver may not satisfy all the integer restrictions. Under such situations, the routine Round $\left(S_{i}^{\prime}\right)$ constructs the smallest closed and bounded convex set $C$ containing the 
solution $\left(S_{i}^{\prime}\right)$ such that the vertices of the convex set $C$ satisfy all the integer restrictions. A vertex of the convex set $C$ is called a feasible vertex if the corresponding solution satisfies the constraints (2) to (13). Furthermore, this routine chooses the best solution $S_{i}^{*}$ from a set of $n^{2}$ feasible solutions corresponding to randomly chosen $n^{2}$ feasible vertices of the convex set $C$. Since the number of vertices of convex set $C$ increases exponentially with $n$, the number of feasible vertices considered was limited to $n^{2}$.

We illustrate our model through an example and compare it with current practice for an assortment of ten products. This data represents an actual (reduced) product assortment of a medium size national grocery retailer obtained by Flynn (2004). The retailer provided all the relevant data including the monthly demand pertaining to 'Baked Beans and Noodles'. The retailer noted that the current practice is to order every month. Table 3 gives the product name, product dimensions $(\mathrm{L}-$ length, $\mathrm{H}-$ height and $\mathrm{D}$ - depth), retail price (RP), wholesale price (WP) and potential demand (PD) that are used in the model consisting of a product assortment of ten products.

Table 3: Product assortment details

\begin{tabular}{|l|c|c|c|c|c|c|}
\hline \multicolumn{1}{|c|}{ Name } & L & H & D & RP & WP & PD \\
\hline Heinz Baked Beans 420G & 110 & 75 & 75 & $\$ 1.22$ & $\$ 1.10$ & 152 \\
HNZ Spaghetti 420 G & 110 & 75 & 75 & $\$ 1.22$ & $\$ 1.10$ & 44 \\
Maggi Two Minute Noodle Chicken 85G & 95 & 140 & 38 & $\$ 0.69$ & $\$ 0.56$ & 34 \\
HNZ Baked Beans 220G & 80 & 74 & 74 & $\$ 0.98$ & $\$ 0.78$ & 27 \\
HNZ Spaghetti EXT Cheesy 420G & 110 & 75 & 75 & $\$ 1.22$ & $\$ 1.10$ & 27 \\
Maggi Two Minute Noodle Beef & 95 & 140 & 38 & $\$ 0.69$ & $\$ 0.56$ & 25 \\
Watties Baked Beans 420G & 110 & 75 & 75 & $\$ 1.16$ & $\$ 0.93$ & 21 \\
HNZ Baked Beans EXT CHEESY 420G & 110 & 75 & 75 & $\$ 1.22$ & $\$ 1.10$ & 21 \\
HNZ Baked Beans S/RED 420G & 110 & 75 & 75 & $\$ 1.22$ & $\$ 1.10$ & 19 \\
SPC Baked Beans 425G & 110 & 75 & 75 & $\$ 1.30$ & $\$ 1.08$ & 18 \\
\hline
\end{tabular}

Table 4 presents the direct space elasticities $\left(\beta_{j}\right)$ and cross elasticities $\left(\delta_{j k}\right)$ generated by Flynn (2004) using the method proposed by Borin et al. (1994). 
Table 4: Product assortment direct space and cross elasticities

\begin{tabular}{|c|c|c|c|c|c|c|c|c|c|c|}
\hline & 1 & 2 & 3 & 4 & 5 & 6 & 7 & 8 & 9 & 10 \\
\hline 1 & 0.10005 & -0.01568 & -0.01630 & -0.00251 & -0.00402 & -0.01029 & -0.01699 & -0.01422 & -0.01881 & -0.01458 \\
\hline 2 & -0.00942 & 0.10302 & -0.01287 & -0.00781 & -0.00392 & -0.00331 & -0.01927 & -0.01361 & -0.01768 & -0.01619 \\
\hline 3 & -0.01560 & -0.00891 & 0.10637 & -0.00237 & -0.00378 & -0.01463 & -0.00529 & -0.00199 & -0.01809 & -0.01687 \\
\hline 4 & -0.01770 & -0.01533 & -0.00829 & 0.22687 & -0.00364 & -0.01890 & -0.00809 & -0.00206 & -0.00661 & -0.01464 \\
\hline 5 & -0.01519 & -0.00150 & -0.00294 & -0.00350 & 0.24393 & -0.01516 & -0.01247 & -0.01001 & -0.01248 & -0.00871 \\
\hline 6 & -0.01663 & -0.01943 & -0.01369 & -0.01995 & -0.01501 & 0.26379 & -0.01342 & -0.00419 & -0.01719 & -0.01495 \\
\hline 7 & -0.01647 & -0.01675 & -0.01691 & -0.00187 & -0.01028 & -0.01933 & 0.27934 & -0.00825 & -0.00509 & -0.00486 \\
\hline 8 & -0.00344 & -0.00207 & -0.00189 & -0.01076 & -0.01912 & -0.01439 & -0.00201 & 0.28448 & -0.01165 & -0.00184 \\
\hline 9 & -0.01761 & -0.00790 & -0.01999 & -0.00321 & -0.01426 & -0.00398 & -0.00961 & -0.00359 & 0.29577 & -0.01857 \\
\hline 10 & -0.00145 & -0.00285 & -0.00146 & -0.00836 & -0.01720 & -0.01463 & -0.00231 & -0.00422 & -0.00275 & 0.29817 \\
\hline
\end{tabular}

For each of the products listed in Table 3 the facing constraints $\left(F_{j}\right)$, maximum facings $\left(u_{j}\right)$ and ordering constraints $\left(Q_{j}^{\min }, Q_{j}^{\max }\right)$ are respectively taken as $L, 12,0$ and 1000 . The available shelf space dimensions (length $B_{S L}$, depth $B_{S W}$ and height $B_{S H}$, in meters) are respectively taken as $3,0.45$ and 0.45 . The volume of the available backroom inventory space $B_{b}$ was taken to be three times that of the shelf space. The unit time considered for the model is one month. Accordingly, the shelf costs $\left(C_{s, j}\right)$, inventory costs $\left(C_{h, j}\right)$ and ordering costs $\left(C_{o, j}\right)$ are taken as $0.5,0.05$ and 0.03 (in \$'s) respectively for all the products. All parameters were supplied by the retailer.

The expected net profit was evaluated corresponding to the allocation strategies given by: (i) the current practice of the retailer (Borin and Farris 1995); and (ii) the solution given by our model. The expected net profit derived through an allocation of shelf space based upon the current practice within one time period (one month) is given in Table 5. 
Table 5: Space allocation and net profit from 'current practice' method

\begin{tabular}{|l|c|r|r|}
\hline \multicolumn{1}{|c|}{ Product Name } & Shelf Allocation & $\begin{array}{r}\text { Backroom } \\
\text { Inventory }\end{array}$ & Net Profit \\
\hline Heinz Baked Beans 420G & 12 & 0 & $\$ 16.24$ \\
HNZ Spaghetti 420 G & 4 & 0 & $\$ 3.74$ \\
Maggi Two Minute Noodle Chicken 85G & 1 & 0 & $\$ 3.59$ \\
HNZ Baked Beans 220G & 2 & 0 & $\$ 4.84$ \\
HNZ Spaghetti EXT Cheesy 420G & 2 & 0 & $\$ 2.59$ \\
Maggi Two Minute Noodle Beef & 1 & 0 & $\$ 2.39$ \\
Watties Baked Beans 420G & 1 & 0 & $\$ 3.92$ \\
HNZ Baked Beans EXT CHEESY 420G & 2 & 0 & $\$ 1.92$ \\
HNZ Baked Beans S/RED 420G & 2 & 0 & $\$ 1.58$ \\
SPC Baked Beans 425G & 1 & 0 & $\$ 3.31$ \\
\hline \multicolumn{2}{|r|}{}
\end{tabular}

Table 6 provides the optimal solution given by our model where the optimal review period works out to be 2.01 (approximately representing eight weeks).

Table 6: Space allocation and net profit determined by the model

\begin{tabular}{|l|r|r|r|}
\hline \multicolumn{1}{|c|}{ Product Name } & Shelf Allocation & $\begin{array}{c}\text { Backrooml } \\
\text { nventory }\end{array}$ & Net Profit \\
\hline Heinz Baked Beans 420G & 10 & 17 & $\$ 39.36$ \\
HNZ Spaghetti 420 G & 2 & 20 & $\$ 9.05$ \\
Maggi Two Minute Noodle Chicken 85G & 2 & 5 & $\$ 7.91$ \\
HNZ Baked Beans 220G & 1 & 15 & $\$ 8.99$ \\
HNZ Spaghetti EXT Cheesy 420G & 1 & 16 & $\$ 4.95$ \\
Maggi Two Minute Noodle Beef & 1 & 14 & $\$ 4.93$ \\
Watties Baked Beans 420G & 1 & 4 & $\$ 8.42$ \\
HNZ Baked Beans EXT CHEESY 420G & 1 & 6 & $\$ 4.19$ \\
HNZ Baked Beans S/RED 420G & 1 & 0 & $\$ 3.79$ \\
SPC Baked Beans 425G & 1 & 0 & $\$ 7.39$ \\
\hline
\end{tabular}

Suppose that the retailer uses the shelf space allocation provided by Table 6 , with zero backroom inventory and one month review period, then the total net profit for a period of length 2.01 is $\$ 92.70$ as compared to $\$ 98.98$ (refer to Table 6) given by our model. Furthermore, the current practice evaluated for a period of 2.01 yields a net profit of $\$ 88.70$. Thus the percentage increase in net profit by our model over the allocation methods (i) and (ii) above are respectively $11.59 \%$ and $6.77 \%$. This increase is of 
significant value to a retailer considering the thin margins under which they operate in the competitive retailing environment.

The above results highlight the significant contribution the optimal review period makes in increasing the net profit. In other words, the current practice does not ensure the best profit in the absence of the optimal review period. If the retailer notices significant changes in his operations, then at the end of the optimal review time, the retailer has the option to change the parameters and resolve the model.

In practice, the optimal review period given by the model may not satisfy the delivery restrictions. We use the above example to illustrate how this situation can be overcome easily. Suppose that the last delivery is made on 20 February, 2006, then according to the above solution the next delivery should be on 17 April, 2006. This date, however, falls on Easter Monday - a public holiday when deliveries are not made. The retailer must adjust the review to occur on either week seven or week nine, whichever is feasible and provides the best net profit. In this case a review in week nine (24 April) provides the best profit of $\$ 107.79$. This translates to an increase in net profit of $8.07 \%$ over the current practice, and is not far off from the near-optimal solution. This demonstrates that the model is flexible enough to accommodate the administrative restrictions of delivery schedules.

\section{Model assessment}

The following discussions provide an assessment of the performance of our model through simulation of three trials of product categories of size 6,10 and 14. Each trial of product category was solved 10 times. The data for product assortment categories was randomly generated from a category of size 300 provided by an independent retailer. For each set of trial data of assortment categories, the problem was solved by the following three methods.

1. Method 1: current practice solution;

2. Method 2: our model restricted to the current practice assortment; and 
3. Method 3: our model without any assortment restrictions (i.e. products are allowed to be excluded from the assortment).

Of the three methods used, Method 3 produced the best solution yielding the maximum total net profit. The percentage increase in the net profit provides a good comparison of Methods 2 and 3 with the current practice. Results of the simulation are summarized in Table 7, giving the mean and standard deviation of the percentage increase in net profit.

Table 7: Product assortment model: comparison with current practice

\begin{tabular}{|c|c|c|c|c|c|c|}
\hline \multirow{2}{*}{$\begin{array}{l}\text { Number of } \\
\text { Products in } \\
\text { the Product } \\
\text { Assortment }\end{array}$} & \multirow{2}{*}{ Allocation Method } & \multirow{2}{*}{$\begin{array}{l}\text { Number } \\
\text { of Runs }\end{array}$} & \multicolumn{4}{|c|}{$\begin{array}{l}\text { Percentage Increase in Net Profit from } \\
\text { the Solution Using Current Practice }\end{array}$} \\
\hline & & & Mean & $\begin{array}{l}\text { Standard } \\
\text { Deviation }\end{array}$ & Min. & Max. \\
\hline \multirow{2}{*}{ Six } & Method 2 & 10 & 10.74 & 6.81 & 0.14 & 20.35 \\
\hline & Method 3 & 10 & 10.77 & 7.63 & 1.41 & 22.13 \\
\hline \multirow{2}{*}{ Ten } & Method 2 & 10 & 3.32 & 0.48 & 2.65 & 3.67 \\
\hline & Method 3 & 10 & 22.01 & 12.92 & 9.60 & 49.86 \\
\hline \multirow{2}{*}{ Fourteen } & Method 2 & 10 & 11.74 & 6.73 & 3.38 & 23.73 \\
\hline & Method 3 & 10 & 23.71 & 10.41 & 3.38 & 34.20 \\
\hline
\end{tabular}

As can be seen form Table 7, our model consistently outperformed the current practice allocation. The significant variation in the percentage increase of the net profit is observed from the entries in the minimum and maximum columns of Table 7. This illustrates the inconsistent performance of the current practice. 
Table 8: Product assortment model: comparison with Borin et al. (1994)

\begin{tabular}{|c|c|c|c|c|}
\hline $\begin{array}{c}\text { Number of } \\
\text { Products in } \\
\begin{array}{c}\text { the } \\
\text { Assortment }\end{array}\end{array}$ & \multicolumn{4}{|c|}{$\begin{array}{c}\text { Percentage Increase in ROI from the Solution Using } \\
\text { The Method of Borin et al. (1994) }\end{array}$} \\
\cline { 2 - 5 } & Mean & $\begin{array}{c}\text { Standard } \\
\text { Deviation }\end{array}$ & Min. & Max. \\
\hline Six & 3.12 & 2.43 & -0.19 & 5.95 \\
\hline Ten & 8.29 & 2.13 & 4.33 & 10.65 \\
\hline Fourteen & 4.75 & 2.21 & 2.06 & 8.68 \\
\hline
\end{tabular}

We have also compared our model with the benchmark literature model of Borin et al. (1994). We have adapted our model by utilizing all the available parameters and used the values given in their paper. Table 8 shows the percentage increase in the return on inventory (ROI) of our model over that used by Borin et al. It can be seen that our model is outperformed only once. In all other instances our method proved to be superior with the mean percentage increase in ROI ranging from $3.12 \%$ to $8.29 \%$ and a maximum increase of up to $10.65 \%$.

\section{Summary}

Our model provides a significant improvement in the net profit compared to that of the current practice and the literature benchmark. Combining the three trials we note that the average percentage increase in the net profit was 13.72. Also, we observe that in at least $30 \%$ of instances the increase in net profit is more than $20 \%$. This result highlights the benefit of using our model.

Figures 2 and 3 present the percentage improvement of the net profit obtained by our method compared to the solution obtained by the current practice, across thirty runs. As can be seen from Figures 2 and 3 , the performance of the current practice allocation is highly fluctuating, with seventy percent of 
the allocations generated by Method 3 resulting in at least a $10 \%$ increase in net profit over the current practice (thirty-three percent for Method 2).

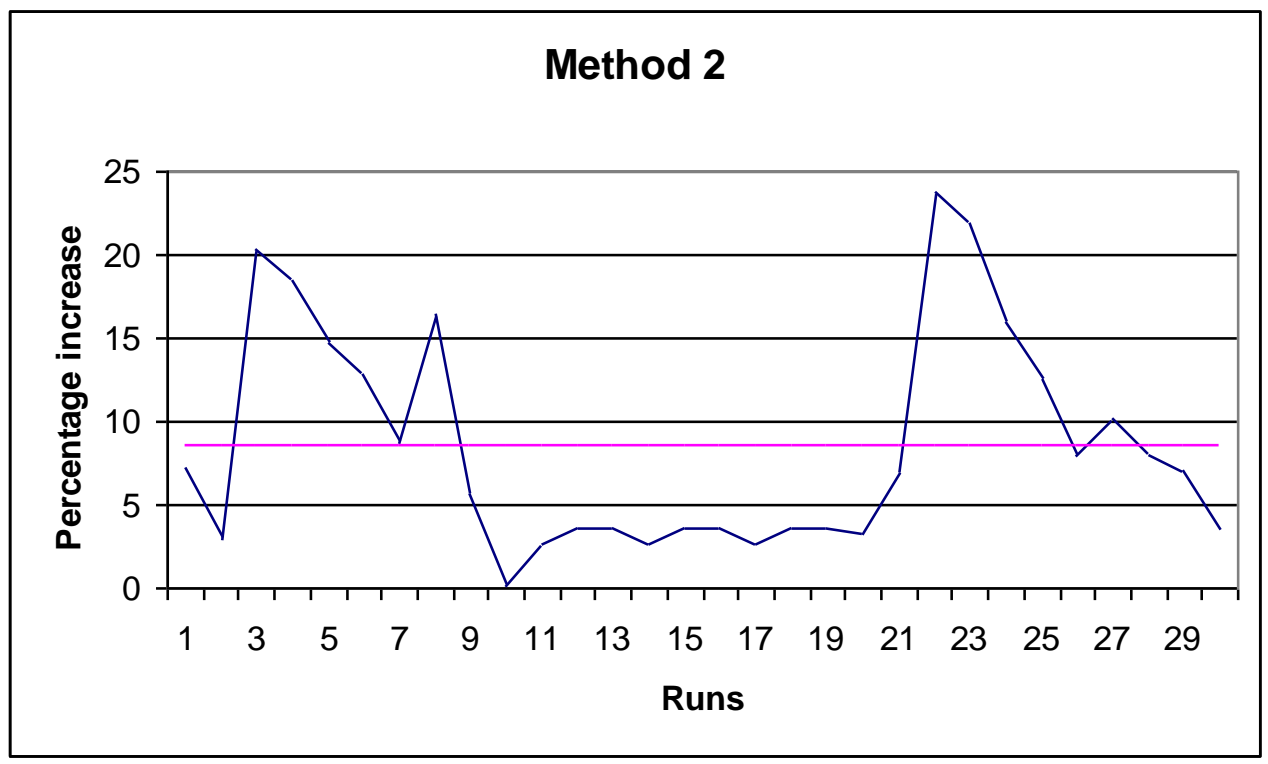

Figure 2: Increase in net profit in comparison with the current practice

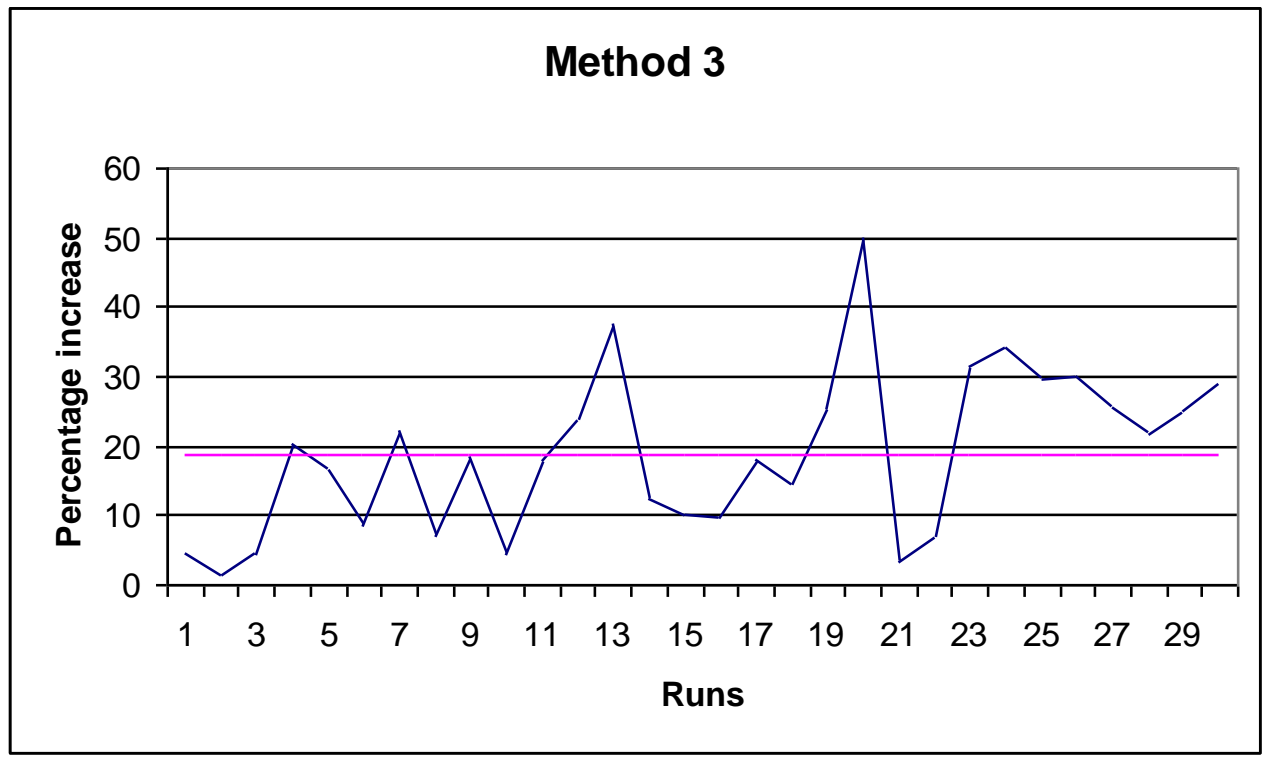

Figure 3: Increase in net profit in comparison with the current practice 
The volatile nature of performance of the current practice raises questions regarding its usage. One of the common features of the retail industries is narrow profit margins that call for a consistently well performing allocation method. Thus our method would be of great benefit to an independent retailer providing an opportunity to change the current practice and increase the net profit considerably. Note that Method 3 gives an average improvement of $18.83 \%$ (indicated by the horizontal line in Figure 3 ) over the current practice. For an independent retailer, Method 3 would be a natural choice to determine shelf space allocations.

\section{Parameter sensitivity analysis}

The parameters of direct shelf space elasticity, cross elasticity and consumer resistance are estimated by the process described by Borin et al. (1994) and they are assumed to be the 'true' values. To understand the robustness of the model we perturb the true values of the input parameters by specified amount, resolve the model and perform sensitivity analysis of the results obtained. The process suggested by (Borin and Ferris 1995) was used to measure the sensitivity of the model.

All the parameters were perturbed uniformly in the same direction, either positive or negative from the true value. The corresponding sensitivity analysis of the results showed that $50 \%$ deviation in either direction of the true value of the parameters resulted in approximately $15 \%$ variation from the net profit yielded by the true value of the parameters. A uniform $10 \%$ parameter estimation error yielded around $4 \%$ variation in the expected net profit using the true values.

Next, each parameter was perturbed randomly in any direction, positive or negative, from its true value. The corresponding model was solved and its solution was compared with the solution obtained for the true value. A mean absolute difference of $17.17 \%$ (from the true parameter values) yielded approximately $7.69 \%$ variation in the net profit from that of the solution obtained from true values of the parameters. A higher mean absolute difference of $66.47 \%$ in the parameter values produced around 
$28.16 \%$ variation in the expected net profit. Thus the model can be considered as a robust model since in real life the error in parameter estimation may not be very large. Our results are similar to that of Borin and Farris (1994, 1995).

\section{CONCLUSIONS}

In the current competitive environment with shrinking margins retailers look for every opportunity to reduce the costs and improve performance. Retail space in general and shelf space in particular, account for a significant element of retailers' costs. Traditionally, these operational factors were not integrated with the market factors while resolving the retailers' management problems. This can be attributed to the weakness in the current shelf space models which solely depend on marketing variables. The enormous benefit derived from the proposed integrated model was clearly demonstrated through model assessment and sensitivity analysis. In particular our model produced an average of 10 to 20 percent improvement over the current industry practice and an improvement of 3 to 8 percent over the model of Borin et al. (1994). Our model could be extended further by distinguishing between the display features of the shelf such as eye level, middle level and top level. The implementation of our model is limited by the capacity of the basic Excel Solver. 


\section{References}

ACNielsen Corporation (2006), http:www.acnielsen.com/products/tools/spaceman.

Anderson, E E and H N Amato (1974), A mathematical model for simultaneously determining the optimal brand collection and display area allocation, Operations Research 22, 13-21.

Bookbinder, J H and F H Zarour (2001), Direct product profitability and shelf space allocation models, Journal of Business Logistics 22, 183-208.

Borin, N, P W Farris and J R Freeland (1994), A model for determining retail product category assortment and shelf space allocation, Decision Sciences 25, 359-384.

Borin, N and P W Farris (1995), A sensitivity analysis of shelf management models, Journal of Retailing $71,153-171$.

Brown, M G and J Y Lee (1996), Allocation of shelf space: a case study of refrigerated juice products in grocery stores, Agribusiness 12, $113-121$.

Brown, W and W T Tucker (1961), The marketing centre: vanishing shelf space, Atlanta Economic Review 4, 9-13.

Bultez, A and P Naert (1988), SH.A.R.P.: shelf allocation for retailers' profit, Marketing Science 7, 211231.

Bultez, A, E Gijsbrechts, P Naert and P V Abeele (1989), Asymmetric cannibalism in retail assortments, Journal of Retailing 65, 153-192.

Cachon, G (2001), Managing a retailer's shelf space, inventory and transportation, Manufacturing and Service Operations Management 3, 211-229.

Campo, K and E Gijsbrechts (2005), Retail assortment, shelf and stockout management: issues, interplay and future challenges, Applied Stochastic Models in Business and Industry 21, 383-392.

Chen, M C and C P Lin (2007), A data mining approach to product assortment and shelf space allocation, Expert Systems with Applications 32, 976-986.

Colville, A R (1968), A Comparative study of nonlinear programming codes, IBM New York Scientific Center Report No. 320 - 2949, IBM Corporation, New York Scientific Center, New York, NY

Corstjens, M and P Doyle (1981), A model for optimising retail shelf space allocations, Management Science 27, 822-833.

Corstjens, M and P Doyle (1983), A dynamic model for strategically allocating retail space, Journal of Operational Research Society 34, 943-951.

Curhan, R C (1973), Shelf space allocation and profit maximisation in retailing, Journal of Marketing 37, 54-60.

Desmet, P and V Renaudin (1998), Estimation of product category sales responsiveness to allocated shelf space, International Journal of Research in Marketing 15, 443-457. 
Dreze, X, S J Hoch and M E Purk (1994), Shelf management and space elasticity, Journal of Retailing 70, 301-326.

Flynn, D (2004), Category management: models and a decision support tool, Honors Dissertation, School of Marketing, Curtin University of Technology, Australia.

Frontline Systems (2006), www.solver.com.

Haggag, A A (1981), A variant of the generalized reduced gradient algorithm for non-linear programming and its applications, European Journal of Operational Research 7, 161-169.

Hansen, P and H Heinsbroek (1979), Product selection and space allocation in supermarkets, European Journal of Operational Research 3, 474-484.

Hwang, H, B Choi and M J Lee (2005), A model for shelf space allocation and inventory control considering location and inventory level effects on demand, International Journal of Production Economics 97, 185-195.

Information Resources Inc. (2006), http://us.infores.com/.

Kao, C (1998), Performance of several nonlinear programming software packages on microcomputers, Computers \& Operations Research 25, 807-816.

Kar, S, A K Bhunia and M Maiti (2000), Inventory of multi-deteriorating items sold from two shops under single management with constraints on space and investment, Computers \& Operations Research 28, 1203-1221.

Lee, W (1961), Space management in retail stores and implications to agriculture, in W K Dolva, ed.: Marketing Keys to Profits in the 1960's (pp. 523-533), Chicago, American Marketing Association.

Lim, A, B Rodrigues and X Zhang (2004), Metaheuristics with local search techniques for retail shelf space optimization, Management Science 50, 117-131.

Ramaseshan, B, N R Achuthan and R Collinson (2008), Decision support tool for retail shelf space optimization, International Journal of Information Technology \& Decision Making 7, 547-565.

Sandgren, E (1981), A statistical review of the Sandgren-Regsdell comparative study, Mathematical programming society COAL meeting proceedings (pp.72-90), Boulder Company.

Urban, T L (1998), An inventory theoretic approach to product assortment and shelf space allocation, Journal of Retailing 74, 15-35.

Urban, T L (2002), The interdependence of inventory management and retail shelf management, International Journal of Physical Distribution and Logistics Management 32, 41-58.

Yang, M H (2001), An efficient algorithm to allocate shelf space, European Journal of Operational Research 31, 107-118.

Zufryden, F S (1986), A dynamic programming approach for product selection and supermarket shelfspace allocation, Journal of Operational Research Society 37, 413-422. 